\title{
Ciudadanía e integración: los derechos sociales y la globalización*
}

Recibido: noviembre 15 de 2011 | Aprobado: mayo 16 de 2012

\author{
Esteban Anchustegui Igartua** \\ esteban.antxustegi@ehu.es
}

\begin{abstract}
Resumen En este artículo se reflexiona sobre los derechos sociales, que son considerados derechos fundamentales y un prerrequisito para la integración política y la autonomía de los ciudadanos. Por tanto, ya se les considere derechos o prerrequisitos para el ejercicio de los derechos, la exclusión del acceso efectivo a ciertos servicios básicos implica una reducción de la ciudadanía como estatus civil y político. Además, la globalización económica ha producido una fuerte restricción en la aplicación estatal de las políticas sociales.
\end{abstract}

\section{Palabras clave}

Derechos sociales, ciudadanía, comunidad política, Estado de Bienestar, dignidad, libertad, igualdad, globalización.

\section{Citizenship and integration: the social rights and glo- balizations}

\begin{abstract}
This article reflects on social rights, which are considered fundamental rights and a prerequisite for political integration and empower citizens. Therefore, been considered as rights or prerequisites for the exercise of rights, the exclusion from effective access to certain basic services imply a reduction of citizenship as civil and political status. Moreover, economic globalization has led to a strong constraint on the state implementation of social policies.
\end{abstract}

\section{Key words}

Social rights, citizenship, political community, welfare state, dignity, freedom, equality, globalization.
* Este artículo presenta resultados parciales de investigación desarrollada en el marco del Grupo consolidado de investigación Parte Hartuz-Democracia participativa (IT300-10 (2010-2012) de la Universidad del País Vasco, España, y subvencionado por el Gobierno Vasco.

** Doctor en Filosofía, Universidad del País Vasco, España. Doctor honoris causa, Universidad Nacional Santiago Abad del Cusco, Perú. Profesor Titular de Filosofía Moral y Política, Facultad de Filosofía y Ciencias de la Educación, Universidad del País Vasco / Euskal Herriko Unibertsitatea, España. 
El debate actual sobre la integración política y la recuperación de la noción de ciudadanía está ligado a la conciencia de que las sociedades modernas precisan de recursos morales para mantenerse. Así, cuestiones como la solidaridad entre ciudadanos con fundamentos individualistas, el modo de integración normativa (ética o jurídica) de una comunidad política o la forma de hacer compatibles los derechos individuales sin prescindir de objetivos colectivos son aspectos que marcan las pautas sobre los modos de relación entre el individuo y la sociedad política o, dicho de otra manera, la forma de encarar los distintos modelos de ciudadanía.

Este debate ha estado protagonizado en las dos últimas décadas por dos corrientes de pensamiento, la de los llamados "liberales" y la de los "comunitaristas", a los se habrá de sumar una "tercera vía" de perfiles más difusos: la de los "republicanos". Con todo, es preciso advertir que se trata de "tipos ideales" en los que encajan mal los autores concretos, y donde, además, el lector puede advertir (con razón) una cierta simplificación en la descripción de los tipos ${ }^{1}$. A continuación haré una breve pincelada de cada una de estas posiciones, exposición que no pretende ser exhaustiva, ni respecto de los autores ni de la complejidad de cada pensamiento, limitándome a señalar algunas de las líneas maestras que subrayan cada una de estas posturas.

\section{La comunidad liberal y los derechos y libertades individuales}

El liberalismo es probablemente la tradición más sólida y constante de la teoría política moderna y, a través de autores que pue-

\footnotetext{
En este aspecto, me adelanto a aceptar la crítica que se me puede hacer, al menos, tanto en la simplificada y quizá estereotipada descripción que realizo del liberalismo, como en la de incurrir en un cierto reduccionismo de la socialdemocracia cuando identifico en demasía esta posición política con el aparente escepticismo que Habermas manifiesta por los derechos sociales. La tesis que yo voy a mantener en este texto es que la garantía de los derechos sociales es fundamental para asegurar la autonomía de las personas, así como su integración política, por lo que considero imprescindible el deber estatal de garantizar a sus ciudadanos el acceso a estas condiciones. Pero también acepto que la garantía de los derechos sociales no es exclusiva de la concepción política que propugna la forma del Estado de Bienestar (aunque sea ésta la más usual y la que con mayor determinación defiende estos derechos, siendo en este sentido el modelo de comunidad política y ciudadanía republicana la que mejor recoge esta posición), sino que también desde algunas posiciones liberales se promueve una defensa de los derechos sociales desde el ámbito de la libertad, e incluso desde otras posturas más eclécticas, que incluyen planteamientos comunitaristas o neoconservadores.
} 
den ir desde Locke hasta Rawls, ha ido construyendo un modo de inserción del individuo en la esfera política propiamente moderna. Insisto también, como señalaba en la nota anterior, que el término liberal es empleado con significados diferentes y que cualquier intento de noción unitaria va a chocar con posiciones bien diferenciadas que, por citar algún caso, pueden ir desde un liberalismo conservador (Hayeck, Nozick...) hasta el liberalismo social propugnado por Rawls o Dworkin. Con todo, para facilitar la visualización de un paradigma liberal autónomo, voy a tratar de reflejar los rasgos comunes que, a modo de «aire de familia»-usando la célebre expresión de Tocqueville- caracterizan las distintas manifestaciones que se identifican con este modelo comunidad política. Sacrifico, por tanto, los matices y las diferencias (muchas de ellas muy significativas) en aras de lograr una abstracción que me va posibilitar entablar una discusión más fructífera entre este modelo y otros ideales de organización política.

Consiguientemente, y para ir definiendo posicionamientos, cabe entender por liberal aquella comunidad política al servicio de la identidad individual. Se enfatiza el individuo y su capacidad de trascender la identidad colectiva, siendo el reconocimiento y la garantía pública de los derechos individuales la piedra angular de este modelo. Y como consecuencia de ello se entiende la ciudadanía como un estatus antes que como una práctica política.

La propuesta liberal, pues, otorga primacía al individuo y sus derechos frente a toda imposición colectiva, para lo cual pone el énfasis en la protección de los derechos de libertad, hasta el punto de percibir las reglas sociales o las leyes como constricciones a su voluntad. El concepto de libertad que propugna es libertad negativa en el sentido más clásico (según la distinción de I. Berlin), como libertad frente al Estado. Ello comporta ciertos presupuestos y entraña ciertas consecuencias para la definición del espacio político y de la acción política. Con todo, en la línea de lo matizado al principio del texto, autores que se autodefinen liberales consideran necesaria la protección de ciertos derechos sociales fundamentales como forma de garantía efectiva de los derechos individuales y antídoto necesario en relación a toda exigencia comunal. 
Así, la sociedad es un conjunto de individuos, y no tiene una entidad propia y diferente de la de sus integrantes, y menos aún fines o intereses propios. Para el liberalismo, en consecuencia, es el individuo quien tiene prioridad ontológica y es el punto de partida a partir del cual, y en función del cual, ha de explicarse cualquier entidad colectiva. Tal individualismo político liberal se encuadra dentro de la tendencia individualizadora general característica de la modernidad, y su modelo emana de las teorías del contrato social, donde la sociedad política resulta del acuerdo entre individuos previamente libres e iguales.

De este modo, la teoría política liberal, heredera del primado de la conciencia individual en la Reforma -así como del cogito cartesiano y de la economía mercantil-subraya la voluntariedad de los vínculos sociales, en contraste con la involuntariedad y la ubicación obligatoria propia de la sociedad estamental y absolutista frente a la que se alza en su origen, al mismo tiempo que introduce, inspirándose en el modelo de la actividad mercantil, una visión competitiva de la vida social. Todo ello implica que el sujeto liberal se concibe como un individuo prepolítico, que considera la libertad como su valor primordial y está definido antes de su integración en una comunidad política y al margen de ella (es alguien que es hombre antes que ciudadano, y desde luego que no es sólo ciudadano). Esta instancia prepolítica está en la base de la noción de sociedad civil lockeana y contiene, desde el planteamiento liberal, el núcleo primordial de derechos e intereses que el Estado debe preservar.

Es cierto que la perspectiva individualista admite varias lecturas desde la propia tradición liberal, ya se considere al hombre como sujeto deseante (Hobbes, Hume o Bentham), o bien como sujeto capaz de autonomía y autodesarrollo (Kant o Mill). Pero, si bien estas tendencias pueden redundar en versiones de la ciudadanía que van desde 'la ciudadanía mínima' a 'la ciudadanía como vía de autorrealización', el compromiso cívico liberal estará siempre condicionado a la realización de los fines individuales. Por consiguiente, quedarían por establecer las reglas para coordinar los intereses contrapuestos, con la aceptación de reglas que posibiliten la coexistencia social, mediante el establecimiento de una neta distinción entre el espacio 
público (que ha de ser compartido por todos) y el ámbito de los intereses y convicciones privados.

El Estado, por lo tanto, es necesario para proteger el conjunto de los derechos individuales que delimitan el ámbito de la libertad privada. Pero la función protectora del Estado comienza y termina con la definición y la protección de los derechos de propiedad. De Jasay llega a hablar de "un Estado sin políticas". Un Estado semejante "se mostrará poco dispuesto a promover el bien de la sociedad, y mucho menos a ordenar a los más afortunados de sus ciudadanos que compartan su fortuna con los menos afortunados, no porque le falte compasión sino porque no considera que tener sentimientos acreditados y honorables faculte al Estado para obligar a sus ciudadanos a compartirlos" (De Jasay, 1993: 44).

Asimismo, las obligaciones cívicas que se le demandan al ciudadano liberal se limitan al respeto de los derechos ajenos y a la obediencia a las leyes emanadas de una autoridad estatal, dependiente en su legitimidad de la preservación de esos mismos derechos. La ética liberal, en consecuencia, es la debida las leyes y está situada dentro del marco de elección y deliberación individual. De hecho, "la dimensión cívica de la existencia es desactivada en provecho de la existencia social y económica que se desarrolla en la esfera de la sociedad civil" (Martínez, 2007: 218). Como consecuencia de ello la propia virtud se privatiza: ya no se refiere al bien público, sino a la honestidad en las transacciones y el respeto a los contratos. En consecuencia, "la teoría y la acción políticas aparecen como meras garantía y protección de la economía de mercado y guiadas por el principio de representación de intereses, pero no como instancia de organización de los recursos sociales a favor del bien común" (Martínez, 2007: 218). Se mantiene así una relación instrumental con la comunidad política, pues ésta no es sino el medio para servir a los individuos y dotarles de libertad y seguridad, con el fin de que cada uno encuentre su propia satisfacción o felicidad.

En este sentido, "no es en la plaza pública, ni por la participación activa en la búsqueda y gestión de un orden justo como el hombre es lo que debe ser, sino en la administración de sus asuntos privados y en la actividad intelectual y productiva por la que, produciendo 
cada vez más y dominando cada vez mejor la naturaleza, llega a la satisfacción de sus deseos" (Spitz, 1993: 33).

También el proceso democrático liberal, subraya Habermas, se rige según el modelo de un compromiso estratégico de intereses entre actores que tratan de alcanzar o mantener sus posiciones de poder (paradigma del mercado). La política tiene como función compatibilizar los intereses privados de los miembros de la sociedad civil (que se distingue netamente del Estado), y los procesos de formación de voluntad están dirigidos únicamente a la legitimación del poder, que descansa en los órganos representativos. Por lo demás, su interés como personas privadas es prioritario, y la participación en la política tiende a limitarse a la opción entre las ofertas de liderazgo político que ofrece el 'mercado político' (Cfr. Habermas, 1998, 1999).

En este contexto, el ciudadano liberal manifiesta una fuerte tendencia a la indiferencia política, que se combina con reclamos imposibles y permanentes. "El fundamento: la puerilidad del ciudadano-consumidor que, reducido a un depósito de satisfacciones, no entiende su vida como su responsabilidad. Su mecanismo: el sistema de competencia política que alienta el cultivo de promesas a unos ciudadanos que entienden la política como una delegación de responsabilidades y como la simple manifestación de unas preferencias que no admiten ni requieren justificación" (Ovejero, 1997: 99). En definitiva, sus actividades se ajustan al patrón de la racionalidad económica: exige el cumplimiento de los contratos o ejerce su capacidad de elección. Y frente a este ciudadano-consumidor estará el político-oferente, el profesional de la política, constituyendo ambos lo que se da en llamar el "mercado político": el votante expresa sus demandas y el político compite por satisfacerlas.

Esta pugna de las élites por la conquista del voto se complementa con la llamada a la pasividad política, donde el compromiso ciudadano intenso con la política es visto como un factor de riesgo, lo cual desbroza el camino a la concepción de la democracia de Schumpeter que, como señalaba antes, se basa en el concepto de competencia por la dirección política: "El método democrático es aquel sistema institucional para llegar a las decisiones políticas, en el que los individuos adquieren el poder de decidir por medio de una 
lucha de competencia por el voto del pueblo" (Schumpeter, 1984: 343), escenario éste donde "aparece el riesgo de sustituir el debate democrático por un juego de negociación entre corporaciones, en el que los intereses de los ciudadanos pueden ser sustituidos $-\mathrm{O}$ simplemente inducidos artificialmente- por los de los grandes agentes económicos" (de Lucas, 1989: 192).

\section{La sociedad comunitarista y la lealtad nacional}

Al contrario de la concepción liberal, el modelo comunitarista puede entenderse como una comunidad política al servicio de la identidad comunal. Desde este punto de vista, el comunitarismo puede entenderse como una crítica a la modernidad o, mejor dicho, como una reacción que señala los efectos negativos que la concepción liberal dominante ha acarreado a las sociedades modernas. Para los comunitaristas, en estas sociedades se habría producido un desarraigo respecto a las tradiciones y los valores comunitarios que proporcionaban la matriz social de las identidades de los individuos, generalizándose, como consecuencia de todo ello, el atomismo, la desintegración social o la pérdida del espíritu público. R. Bellah lo expresa muy gráficamente cuando señala que muchas personas "se dan cuenta de que, si bien los procesos de individuación y separación eran necesarios para liberarnos de las tiránicas estructuras del pasado, deben ser compensados por una renovación del compromiso y de la comunidad, si no queremos que terminen autodestruyéndose, o convirtiéndose en sus opuestos" (Bellah, 1989: 351).

En este sentido, el comunitarismo también implica una crítica a las consecuencias del Estado de Bienestar (aspecto éste que luego trataré más detenidamente), uno de cuyos resultados es haber erosionado las redes de solidaridad y compromiso social que antaño cohesionaban a la sociedad, dejando sin fundamento, a falta de valores compartidos, las apelaciones a la ciudadanía (Cfr., Colom, 1994). En definitiva, que la erosión y la desaparición de estas redes y valores comunitarios habría conducido, según los comunitaristas, a "la fragmentación, esto es, un pueblo cada vez menos capaz de formar un propósito común y llevarlo a cabo. La fragmentación aparece cuando las personas llegan a verse a sí mismas cada vez más atomísti- 
camente y cada vez menos ligadas a sus conciudadanos en proyectos comunes y lealtades" (Taylor 1998: 138).

Como afirman los comunitaristas, el yo siempre es un yo situado en una sociedad particular, en una situación histórica concreta. Ese "yo histórico" engendra deberes hacia las familias, los grupos y las naciones que participan de la definición de nuestro yo. Estos deberes pueden ser comprendidos como una expresión de autoestima o de aceptación de uno mismo. Para aceptarme o amarme a mí mismo debo respetar y querer los aspectos de mí mismo que están ligados a los otros. Así, mi simple biografía crea obligaciones hacia otras personas, obligaciones que yo condenso bajo la noción general de lealtad. De esta manera, los vínculos de afecto y lealtad hacia la propia comunidad proveen de identidad y motivación política a los individuos (Cfr., Beiner, 1977). En conclusión, la sociedad vendría a ser como una sucesión de círculos concéntricos, con el Estado como círculo máximo; así, como círculos concéntricos, las distintas comunidades, desde la familia a la nación, mantienen una continuidad cualitativa con diferencias derivadas únicamente de la frecuencia de encuentros o relaciones, no de los valores. A lo largo de las distintas escalas, el cemento que mantiene la unidad es la participación en la misma idea de bien.

El deber primordial es, pues, el debido a la comunidad, o a los conciudadanos en cuanto pertenecientes a esa comunidad o a esa identidad nacional (en el caso del nacionalismo). Es el compromiso con una concepción común de la vida buena, con una comunidad moral y política específica, que sólo puede ser asumida por quienes pertenezcan a ella. En el nacionalismo, además, se considera la nacionalidad como prerrequisito de la solidaridad y como condición de la identidad y de la legitimación del Estado. Se propugna, por tanto, el patriotismo nacional, definido como "un tipo de lealtad a la propia nación, lo que sólo aquellos que poseen esa particular nacionalidad pueden alegar" (MacIntyre, 1995: 210), al que se considera como una virtud, puesto que es la condición de posibilidad del desarrollo de la conciencia moral de los individuos.

Una posición semejante es defendida por Taylor (Cfr. 1990) cuando se vale del término 'atomismo' para referirse a las doctrinas contractualistas, las cuales, proclamando la autosuficiencia del indi- 
viduo, consideran al sujeto humano como un portador de decisiones incomunicado que calcula racionalmente sus acciones. Para Taylor, esta noción atomista de la naturaleza humana y de la prioridad a ultranza del individuo y de sus derechos sobre lo social acarrea una visión puramente instrumental de la sociedad.

Frente a esa posición individualista, Taylor argumenta que incluso aquellas concepciones de lo humano que consideran central la libertad y la autonomía han de reconocer que ésta sólo es posible en el marco de un cierto tipo de sociedad que permite desarrollar la capacidad necesaria para ejercitarlas: "el desarrollo de la libertad requiere cierta comprensión de sí mismo, en la que las aspiraciones a la autonomía y a la orientación son concebibles; y, en segundo lugar, que esta comprensión de sí mismo no es una idea que podamos defender solos, sino que nuestra identidad se ve siempre en parte definida en relación con otros o a través de la visión comunitaria que subyace a las prácticas de nuestra sociedad" (Taylor, 1990: 123). En este sentido, el ser humano no puede desarrollar su autonomía moral al margen de una política cultural mantenida por instituciones de participación política y garantías de independencia personal, esto es, que "la identidad del individuo autónomo y autodeterminado requiere una matriz social que reconozca, por ejemplo, a través de una serie de prácticas, el derecho a la decisión autónoma y que defienda que el individuo tiene voz en la deliberación sobre la acción pública (Taylor, 1990: 123).

En el fondo, lo que Taylor está contraponiendo son dos versiones de la libertad humana y de la identidad: "Por tanto, la cuestión que se plantea entre los atomistas y sus oponentes es profunda; afecta a la naturaleza de la libertad, y más allá todavía, se plantea qué significa ser un ser humano; qué es la identidad humana y cómo se defiende y mantiene" (Taylor, 1990: 123). Y frente al engaño de la autosuficiencia que impide ver que el individuo libre, el que detenta los derechos, sólo puede asumir esta identidad gracias a su relación con una civilización liberal desarrollada, Taylor sostiene que ese individuo situado en el estado de naturaleza "nunca podría alcanzar la identidad y por tanto nunca podría crear por contrato una sociedad que lo respete. Más bien, el individuo libre que se afirma como tal ya tiene una obligación de completar, de restaurar o de mantener la 
sociedad dentro de la cual es posible alcanzar esta identidad" (Taylor, 1990: 124).

Así, la crítica comunitarista mostraría no sólo el carácter ilusorio del yo independiente de sus contextos, sino también, y paradójicamente, la necesidad de partir de una base comunitaria para el proyecto de autorrealización del propio yo autónomo moderno (Cfr., Baccelli, 1994). Y, en este marco, la defensa de los derechos y la afirmación del valor de los individuos dependen de ciertas capacities (aspecto que luego destacaremos al hablar de la ciudadanía social) que hacen humana una vida, y que como tales requieren respeto. Y este respeto implica una "obligación de pertenecer" a la forma social que la hace posible (Cfr., Taylor, 1990). La alternativa comunitarista, en consecuencia, subraya que el sujeto no tiene una identidad previa a su comunidad, sino que "la pertenencia a la sociedad es la que le proporciona los valores desde donde puede escoger y juzgar. Los valores comunitarios dotan de sentido a su vida y elecciones" (Ovejero, 1997: 100).

Para los comunitaristas, por tanto, la socialización moral de los individuos tiene lugar en el seno de una comunidad particular, y la primacía liberal del individuo y sus derechos es sustituida por la primacía de la comunidad. Así, si para los liberales la universalidad y generalidad características de las reglas morales se alcanzan elevándose por encima de la particularidad social en la que se originan, para los comunitaristas estas reglas morales se alcanzan a partir de los bienes específicos y relativos en virtud de los cuales se justifican. Como consecuencia de todo ello, insiste el comunitarismo, cualquier sociedad necesita (e implica) un conjunto de valores que presiden las relaciones sociales. De hecho, la opción liberal por la neutralidad no es sino una opción valorativa más, que presenta el riesgo añadido de conducirnos a una sociedad en la que la falta de valores comunes y metas compartidas conduce a la desintegración, la apatía y el escepticismo, e incluso a la corrupción y la violencia política.

Recapitulando, los comunitaristas sostienen que una sociedad basada meramente en la garantía de los derechos individuales fundamentales carece de fuerza motivadora e integradora capaz de proporcionar cohesión y solidaridad en grado suficiente para el mantenimiento de la sociedad. Frente a la visión contractualista de la 
sociedad como una cooperación instrumental entre los individuos para sus fines privados, el comunitarismo sostiene que es necesaria una concepción común de lo bueno que proporcione un horizonte colectivo de valor y comprensión.

\section{El modelo republicano y la virtud cívica}

Cuando se habla de modelo republicano es conveniente aclarar el significado terminológico del término. Si bien es cierto que en su origen el significado del concepto república está reñido (aunque no solamente) con formas de gobierno como monarquía o aristocracia (o a sus respectivas degradaciones, como el despotismo o la oligarquía), el uso contemporáneo que se hace del término republicano tiene poco que ver con el que corresponde a su historia pasada. En su horizonte están las formas de gobierno que se inspiran en los modelos democráticos de la Grecia clásica y, sobre todo, la Roma republicana, las repúblicas y ciudades libres italianas y de otros muchos países europeos que en el Renacimiento defienden su autonomía frente al modelo absolutista que acaba imponiéndose, o los que recogen aspectos más radicalmente igualitarios y fraternos de las revoluciones francesa y norteamericana. Esta tradición, recogida y analizada por una magnífica labor de historiadores (J. G. A. Pocock, H. Baron, Q. Skinner, C. Nicolet, etc.) ha sido reelaborada y actualizada, tomando cuerpo en numerosos pensadores políticos que ahondan en la crisis de legitimidad de las democracias representativas.

Teniendo en cuenta todo este bagaje, el modelo de comunidad política republicana puede entenderse como una manifestación de la identidad cívica. Es decir, como aquella concepción de la vida política que preconiza un orden democrático dependiente de la vigencia de la responsabilidad pública de la ciudadanía. Por ello, su institución fundamental es precisamente la de la ciudadanía, en su doble sentido ${ }^{2}$ : como conjunto de miembros libres de la sociedad política y como la condición que cada uno de ellos ostenta en tanto que componente soberano del cuerpo político.

Doble sentido que se expresa con dos términos distintos tanto en inglés -citizenship / citizenry-como en alemán -Bürgerschaft / Bürgertum-. 
Aunque comparte algunos de sus supuestos con el liberalismo y otros con el comunitarismo, no se confunde con ninguno de los dos. Tiene en común con el comunitarismo el hecho de que el ciudadano republicano también se sabe ligado, a la hora de configurar sus preferencias y su identidad, con su sociedad, y en que otorga importancia a la responsabilidad y a las obligaciones comunes. Asimismo, participa de la crítica a la concepción individualista del liberalismo y su concepción puramente procedimental de la comunidad política. Sin embargo, frente al comunitarismo, el republicanismo no necesita compartir una noción cultural de una comunidad prepolítica, ni una idea sustantiva del bien común.

Es cierto que el comunitarismo y el republicanismo tienen una fuerte vinculación con la historia y las tradiciones propias de la comunidad, pero a la hora de valorar y respetar estas tradiciones es muy distinta la posición comunitarista frente a la republicana. Así, si para la primera es muy importante el ejemplo del pasado, la mirada republicana no se siente involucrada con las decisiones pretéritas. Su posicionamiento está abierto al futuro, al tipo de comunidad que quiere construir la comunidad viviente. Su proyecto, desprovisto de narraciones vinculantes con el pasado, se vincula a las generaciones actuales, cuya plena autonomía debe garantizarse para decidir cuál es el modo en que quiere vivir.

Por otra parte, también, el republicanismo comparte con el modelo liberal la importancia que ambos conceden a los derechos y a la libertad negativa. El republicanismo hace suya la afirmación moderna de la autonomía y el pluralismo. Considera que la libertad está ligada a la garantía del orden normativo equitativo creado y mantenido por las instituciones públicas, en tanto éstas se nutren de la participación y el cumplimiento del deber cívico por parte de los ciudadanos. Así, mientras los liberales asocian siempre la libertad a la no interferencia, los republicanos lo ligan con la ciudadanía entendiéndola como "no-dominación". Es decir, entienden la libertad como la garantía de no interferencia arbitraria por los demás en el ámbito legítimo de acción que se le reconoce a cada uno (sería un concepto más cualitativo que cuantitativo).

Asimismo, el republicanismo concibe la ciudadanía principalmente como práctica política, como forma de participación activa 
en la cosa pública. No se asienta sobre la primacía ontológica del individuo, ni sobre la defensa de sus derechos particulares, sino sobre un modo de vida compartido. De hecho, desde el republicanismo no cabe hablar de "derechos naturales" (la naturaleza sólo produce fuerza y rivalidad; sólo mediante la ley se pasa del desequilibrio y el enfrentamiento de hecho a la igualdad en derechos que nos pongan a salvo de la arbitrariedad), sino que habría de hablarse de derechos ciudadanos, es decir, derivados de acuerdos y normas, resultados de un proceso político, y no su presupuesto. La igualdad y los derechos están, por tanto, basados en el autogobierno, que requiere de la participación activa de la comunidad política.

La virtud cívica, pues, sería la debida al marco universal de la constitución democrática, es decir, a la ley, como lo que permite y consolida la diferencia, el respeto a lo particular y la convivencia tolerante y pacífica en la diversidad. Y lo mejor para defender esa libertad como no dominación es uniéndola a la ley y al sistema político que ella produce. Se trataría de una relación no instrumental con la comunidad política, por cuanto ésta se considera como un bien en sí misma. Es decir, más que en derechos, la ciudadanía republicana se basaría en deberes. Así, un republicano como Skinner, frente a la idea de Dworkin -que entiende los derechos como "cartas de triunfo"- defiende que los individuos deben comenzar a "colocar sus deberes de participar activamente en la vida política de la comunidad por encima de sus derechos" (Gargarella, 1999: 176-177). Esta posición implicaría que el Estado liberal abandonase su neutralidad respecto a las concepciones del bien que sus miembros escogen.

Este será uno de los reclamos distintivos del republicanismo a lo largo de toda su historia: el de subordinar la organización política y económica de la sociedad a la obtención de buenos ciudadanos, pretensión que siempre ha tendido a ser rechazada por el liberalismo. Por ello nada tiene de extraño que una posición netamente republicana fomente programas públicos de educación cívico-democrática, de manera que la ciudadanía pueda ser ejercida en modo mínimamente competente y responsable. La consecuencia más inmediata es que la política democrática dejará de ser un asunto exclusivo -y excluyente- de unos pocos (la clase política) para pasar a ser un asunto de una amplia mayoría consciente de sus derechos y de sus 
responsabilidades, y dispuesta a exigir a los gobernantes el fiel cumplimiento de sus tareas (gobierno representativo).

Así, en la medida en que la ciudadanía implica una capacidad de reivindicar y obtener la efectividad de los derechos, "el status de ciudadano fija en especial los derechos democráticos de los que el individuo puede hacer reflexivamente uso para cambiar su situación, posición o condición jurídica material” (Habermas, 1998: 626). Porque "la autonomía política -recuerda Habermas- es un fin que nadie puede realizar por sí solo" (1998: 627) es por lo que los derechos, además de precondición de la democracia, son a la vez resultado de la misma.

\section{Desarrollo de la ciudadanía e igualdad de derechos}

En principio parece evidente que la reivindicación republicana de la participación activa en la cosa pública y la defensa de un modo de vida político y democrático compartido sólo sería posible si al mero estatus formal del ciudadano como titular de ciertos derechos y miembro pleno de la comunidad política se unen condiciones materiales que posibilitan el ejercicio efectivo de dicho estatus, aspecto éste al que se hace referencia cuando se reivindican los derechos sociales.

La reclamación, por tanto, de una ampliación de la noción de ciudadanía en esta dirección se sigue de la consideración de que el ejercicio de los derechos políticos depende de una serie de condiciones previas, que no son sólo económicas, pero están casi siempre ligadas a la renta percibida, y que de hecho implican la exclusión o inclusión de la ciudadanía. Esta evidencia de que existe un fuerte vínculo entre ciudadanía y condiciones materiales no es algo nuevo, y se ha manifestado en un debate secular sobre la relación entre el ideal (la noción normativa) de ciudadanía y la creación, adquisición y posesión de riquezas (Cfr. Oliver/Heater, 1944). Por consiguiente, el estatus de ciudadano está ligado, tanto en la tradición clásica como en la moderna, a dos requisitos: la posesión de ciertos bienes o patrimonio, y una cierta igualdad entre quienes participan en la vida pública (Cfr. Brillante, 1994). 
Así, Aristóteles pensaba que un cierto nivel de prosperidad material era necesario para ser ciudadano -al menos, para serlo adecuadamente-, más aún teniendo en cuenta el proyecto colectivo que supone la polis: "Si la asociación política sólo estuviera formada en vista de la riqueza, la participación de los asociados en el Estado estaría en proporción directa de sus propiedades, y los partidarios de la oligarquía tendrían entonces plenísima razón (...). Pero la asociación política tiene por fin, no sólo la existencia material de todos los asociados, sino también su felicidad y su virtud" (Aristóteles, 1941: III, 5).

Similares consideraciones pueden encontrarse en Kant, cuando afirma que "sólo la capacidad de votar cualifica al ciudadano; pero tal capacidad presupone la independencia del que, en el pueblo, no quiere ser únicamente parte de la comunidad, sino también miembro de ella, es decir, quiere ser una parte de la comunidad que actúa por su propio arbitrio junto con otros (...), y en general cualquiera que no puede conservar su existencia (su sustento y protección) por su propia actividad, sino que se ve forzado a ponerse a las órdenes de otros (salvo a las del Estado), carece de personalidad civil y su existencia es, por así decirlo, sólo de inherencia” (Kant, 1989: I, §46). Esta distinción entre ciudadanía activa y pasiva también está implícita en la Declaración Universal de Derechos del Hombre y del Ciudadano de 1789, cuando en el artículo 2 se dice que "la finalidad de todas las asociaciones políticas es la protección de los derechos naturales e imprescriptibles del hombre; y esos derechos son la libertad, la propiedad, la seguridad y la resistencia a la opresión”. El ejercicio de la ciudadanía, por tanto, tiene en la propiedad uno de sus de rasgos básicos.

La crítica marxista, evidentemente, analiza el aspecto opuesto, y denuncia la hipocresía que supone que "el Estado suprime a su manera las diferencias de nacimiento, de estamento, de cultura, de profesión, declarando no políticas las diferencias de nacimiento, estamento, cultura, profesión; cuando proclama, desconsiderando dichas diferencias, a cada miembro del pueblo partícipe en igual medida de la soberanía popular" (Marx, 1997: 24), de lo que se desprende que esa declaración de igualdad enmascara la desigualdad existente 
entre los individuos y oculta la determinación de las relaciones políticas por la estructura social. En definitiva, el acceso o no a unas condiciones materiales de vida determina la exclusión real de los derechos, en clara alusión a una manifiesta relación entre economía (mercado) y política (ciudadanía).

Y será Marshall, en su famosa conferencia de 1949, quien ponga el dedo en la llaga al afirmar: "La ciudadanía es un status que se otorga a los que son miembros de pleno derecho de una comunidad. Todos los que poseen ese status son iguales en lo que se refiere a los derechos y deberes que implica" (1997: 313). A continuación, Marshall constata que, "por otra parte, la clase social es un sistema de desigualdad (que) al igual que la ciudadanía, puede basarse en un conjunto de ideales, creencias y valores", de lo que concluye: "Es, por tanto, razonable pensar que la influencia de la ciudadanía en la clase social debe adoptar la forma de un conflicto entre principios opuestos" (1997: 313).

En esta conferencia Marshall subraya que la ciudadanía ha sido una institución que se ha desarrollado en Inglaterra al menos desde la última parte del siglo XVII, de donde resulta evidente que su incremento coincide con el surgimiento del capitalismo, al que califica "que es un sistema no de igualdad, sino de desigualdad" (1997: 313). Y llegado a este punto se hace la siguiente pregunta: "Hay algo aquí que necesita explicación. ¿Cómo es posible que esos dos principios opuestos pudieran crecer y florecer codo con codo en un mismo suelo? ¿Qué hizo posible que se reconciliaran mutuamente y que llegaran a ser, al menos por un tiempo, aliados en lugar de antagonistas? La cuestión es pertinente, pues es claro que en el siglo XX la ciudadanía y el sistema de clases del capitalismo han estado en guerra" (1997: 313).

Marshall equipara el desarrollo de la ciudadanía con la instalación progresiva de los derechos y la efectiva garantía de su disfrute, todo ello en el horizonte de ser miembro pleno de la sociedad. Y este proceso tiene sus etapas históricas: "no es extraño que la sociedad capitalista del siglo XIX tratase los derechos políticos como un subproducto de los derechos civiles" (1997: 308); "cuando asigné cada uno de los períodos de formación de los tres elementos de la ciudadanía a un siglo diferente -los derechos civiles al XVIII, los 
políticos al XIX y los sociales al XX- ya dije que estos dos últimos se solapaban bastante" (1997: 308); "el siglo XIX fue en su mayor parte un período en el que se sentaron las bases de los derechos sociales, pero aún entonces se negaba expresamente o no se admitía definitivamente el principio de los derechos sociales como parte esencial del status de ciudadanía" (1997: 310), o "los derechos sociales se redujeron hasta casi desaparecer en el siglo XVIII y principios del XIX. Comenzaron a resurgir con el desarrollo de la educación elemental pública, pero hasta el siglo XX no llegarían a equipararse con los otros dos elementos de la ciudadanía" (1997: 312). Así, señalando estos hitos, y a través de ellos, Marshall interpreta la historia del Occidente moderno desde el punto de vista, no de las instituciones, sino del individuo y sus derechos.

\section{La naturaleza de los derechos sociales y el Estado de Bienestar}

La naturaleza de los derechos sociales es una cuestión altamente controvertida, y el dilema se plantea entre quienes los consideran derechos de igualdad y entre los que sostienen que estaríamos ante unos derechos de libertad con componente igualitario. La tesis de que estamos ante unos derechos de igualdad tendría su fundamento en que a través de los derechos sociales "pretenden garantizarse ciertas condiciones mínimas a la población mediante el cumplimiento del ordenamiento" (Cossío Díaz, 1989: 46). Para los defensores de la segunda opción, al contrario, todos los derechos son derechos de libertad, sean derechos que tengan un componente igualitario, sean económicos, sociales o culturales: el elemento inherente a todos los derechos es potenciar y reforzar la libertad para todos (Cfr. PecesBarba, 1988: 213). Según este autor, "derechos fundamentales de cualquier tipo y realización integral de la libertad como libertad autonomía, como superación de los obstáculos que hacen posible el desarrollo en todas las facetas de la condición humana son lo mismo, en su horizonte todavía en parte utópico, pero no imposible en el desenvolvimiento histórico de la sociedad democrática" (PecesBarba, 1988: 213). 
Con todo, este último posicionamiento tiene su contestación en que la opción radical por la libertad sin su práctica moral puede provocar graves fracturas y desigualdades en la comunidad. Como afirma R. Alexy, "el conjunto de leyes de una sociedad, positivamente formuladas, no es todo el derecho de las personas, sino la concreción de la limitación de algunos derechos que los socios ponen en común; limitación que mutuamente respetarán para un mejor ejercicio de los propios derechos, en particular del uso moral de la libertad, la cual es el origen de todos los derechos de las personas" (2004: 21).

Marshall sostiene que "con el elemento social me refiero a todo el espectro desde el derecho a un mínimo de bienestar económico y seguridad al derecho a participar del patrimonio social y a vivir la vida de un ser civilizado conforme a los estándares corrientes en la sociedad" (1997: 302-303). El objetivo está marcado y con la demanda de reconocimiento de los derechos sociales surge un conflicto entre la ciudadanía plena y el sistema de desigualdades en los que se basa el capitalismo, lo que Marshall, de una forma novedosa para ese momento, trata de romper entre el estatus del ciudadano y la posición en el sistema de clases, desvinculando de las vicisitudes del mercado, la universalidad y la eficacia de los derechos de ciudadanía. Porque, en definitiva, como dice Dahrendorf: "tolerar que una clase baja es económicamente factible y no representa costos políticos (...) delata una disposición a suspender los valores básicos de la ciudadanía (derechos de participación iguales para todos) para una categoría entera de personas, lo cual debilita las pretensiones universales intrínsecas de esos valores. (...) La mayoría pagará un alto precio por dar la espalda a aquellos que fracasan repetidamente, y el hecho de que este precio sea moral más que económico no debe engañar a nadie respecto de su importancia" (1997: 145).

Por tanto, para Marshall, la ciudadanía social "abarcaría tanto el derecho a un modicum de bienestar económico y seguridad, como a tomar parte en el conjunto de la herencia social y vivir la vida de un ser civilizado, de acuerdo con los estándares prevalecientes en la sociedad" (Gordon, 2003: 9). Se aboga pues por realizar un esfuerzo para que todos los miembros de la sociedad cuenten con una situación material que les permita gozar y ejercitar su igualdad jurídica; y corresponde al Estado cumplir ese objetivo social. 
En este sentido, Contreras Peláez sostiene que "allí donde no hay una intervención correctora de los poderes públicos, la libertad se convierte en coartada para la explotación de los débiles y la igualdad formal deviene cobertura ideológica de la desigualdad material. Los derechos sociales han sido introducidos precisamente para enmendar este despropósito; la política social del Estado debe ser, por tanto, un agente compensador-nivelador que contrarreste (en parte) la dinámica de desigualdad generada por la economía de mercado" (1994: 26).

Es precisamente en este contexto del «Estado como agente compensador-nivelador» donde se desarrolla la formulación del «Estado del Bienestar». Para esta propuesta de organización político-social, en aras de garantizar las capacidades acompañantes de una ciudadanía plena -entendida como igualdad de estatus o de dignidad social-, para la equiparación jurídica de los ciudadanos -al objeto de favorecer su plena autonomía- es necesaria una equiparación fáctica. Y todo ello exige el reconocimiento y establecimiento de derechos fundamentales de tipo social, que tienen que ser proporcionados por el Estado.

Y será justamente el ensayo de Marshall uno de los primeros exponentes teóricos del llamado Estado de Bienestar (o Estado social), que por aquellos años se iniciaba en Gran Bretaña. Por tanto, las compensaciones y prestaciones del «Estado social» establecen "la igualdad de oportunidades para poder hacer un uso de las facultades de acción jurídicamente garantizadas que quepa considerar igual" (Habermas, 1998: 499). Los derechos sociales, en suma, deben ser reconocidos como derechos esenciales, porque aseguran los requisitos mínimos de una vida digna y son presupuesto del ejercicio de los derechos fundamentales civiles y políticos.

Con todo, los críticos del Estado de Bienestar han puesto en tela de juicio, por sus consecuencias negativas, los llamados derechos sociales, (aunque, de hecho, estos derechos no gozan de reconocimiento y protección comparables a los civiles y políticos, incluso en las Constituciones de los Estados del Bienestar $\left.{ }^{3}\right)$. A ello se une, además, lo impreciso de su objeto (p. ej. ¿cómo se entiende el derecho

\footnotetext{
3 Ver p. ej. la Constitución española, donde el derecho al trabajo, a la vivienda, la salud, el medio ambiente, etc. se incluyen en el capítulo de "Principios rectores de la vida social y económica", por lo que no pueden invocarse estrictamente como derechos subjetivos vinculantes para los poderes públicos.
} 
al trabajo?: a un puesto de trabajo o a una prestación por desempleo (Cf. Alexy, 1997: 490-491).

Para la crítica que se hace desde los grupos neoconservadores y neoliberales los derechos sociales y las políticas del Estado del Bienestar son extraordinariamente costosas y se hacen en detrimento de otras posibles inversiones; pueden llegar a socavar los derechos de propiedad a través de los impuestos y la libertad de los ciudadanos para disponer de sus bienes, llegando a afectar a sus derechos fundamentales e invalidar sus derechos civiles; conducen a la dependencia y la pasividad (cultura de la dependencia), en vez de estimular la iniciativa y la responsabilidad de los individuos; y son conflictivos, ya que la escasez de recursos suscita conflictos y conduce a un cálculo utilitario de derechos, contradictoria con la idea de la garantía de universalidad de los derechos.

Asimismo, desde propuestas políticas más cercanas a la socialdemocracia («Tercera Vía», «Nuevo Centro») se han señalado las consecuencias negativas que las prácticas del Estado de Bienestar acarrean para la ciudadanía. Así, se advierte de que las prestaciones sociales del Estado del Bienestar son peligrosamente compatibles con un paternalismo no democrático (de hecho, en los países del «socialismo real» hubo derechos sociales sin derechos civiles y políticos), y susceptibles de fomentar una degradación «clientelar» de la ciudadanía (voto de «clientes», condicionado a los servicios ofrecidos). En esta dirección Habermas ha observado los peligros de asumir irreflexivamente que la mera inclusividad de los derechos sociales conlleve per se un incremento de la autonomía efectiva en los ciudadanos, ya que tales derechos pueden también ser otorgados de modo paternalista: "Ciertamente, tanto las libertades subjetivas como tales [sic] derechos sociales pueden considerarse como base jurídica de esa autonomía social que es la que empieza haciendo efectiva la realización de los derechos políticos. Pero éstas son relaciones empíricas, no relaciones conceptualmente necesarias. Pues los derechos de libertad y los derechos sociales pueden asimismo significar la cuasi renuncia privatista a un papel de ciudadano, que se reduce entonces a relaciones de clientela con unas administraciones que otorgan sus prestaciones en términos paternalistas" (Habermas, 1998: 142-143). Desde esta perspectiva, el Estado del Bien- 
estar habría favorecido más bien la heteronomía y la pasividad de los ciudadanos, e incluso puede afectar a la autonomía privada de éstos, en cuanto impone una «normalización» y un control tutelar preocupantes.

Por último voy a referirme al ensayo de Barbalet Citizenship Citizenship: Rights, Struggle and Class Inequality $(1988)^{4}$, al que considero uno de los estudios críticos más sugerentes y destacados sobre la perspectiva marshalliana de los derechos sociales. En primer lugar, Barbalet advierte que los derechos de ciudadanía no son en sí mismos homogéneos, sino que, al contrario, tanto en su origen como a través de su desarrollo, se hallan en permanente tensión. Y esta mutua rivalidad es aún más ostensible entre los derechos civiles, cuyo ejercicio acentúa el poder político y económico de quien los disfruta, y los derechos sociales, simples derechos de consumo que no otorgan ningún tipo de poder a sus titulares. Por tanto, los denominados «derechos sociales», que son inherentes al «Estado de Bienestar», no poseen capacidad alguna de alterar las relaciones de poder en la esfera productiva, ya que sólo afectan a los mecanismos de la distribución de recursos, pero no tienen ninguna influencia sobre los aparatos de producción. Más aún, los derechos sociales sólo son beneficios proporcionados por el Estado, mientras que los derechos civiles y políticos, a diferencia de los anteriores, se sostienen y ejercen contra el Estado. Por tanto, desde este punto de vista, sería absolutamente razonable cuestionar la propuesta que incluye a los derechos sociales entre los derechos de ciudadanía. De hecho, la tesis de Barbalet lleva a considerarlos como conditional opportunities, esto es, meros instrumentos para el ejercicio efectivo de los derechos civiles y políticos.

Empero, sean los derechos sociales derechos, o sean condiciones necesarias para el ejercicio de los derechos civiles y políticos, parece evidente que para ser miembro pleno de una comunidad política al estatus formal del ciudadano han de unirse condiciones materiales que posibilitan el ejercicio efectivo de dicha condición, o, formulado de otro modo, que "la libertad jurídica para hacer u omitir algo

4 Las referencias a este ensayo están tomadas de D. Zolo (1994). 
sin la libertad fáctica carece de todo valor" (Alexy, 1997: 486). Pero aceptar esto lleva a hacernos la siguiente pregunta: ¿qué recursos hay que poner a disposición de cada persona para que pueda asumir plenamente la condición de ciudadano?

\section{Globalización y neoliberalismo}

Con todo, en los últimos decenios se ha impuesto una nueva forma de organización territorial y política del sistema mundial, donde, con la expansión del sistema económico capitalista neoliberal, el Estado ha sido desplazado y ha perdido gran parte de su función reguladora. En efecto, con la globalización y el neoliberalismo se ha multiplicado el proceso de expansión de las empresas multinacionales y el aumento de su peso específico en la producción mundial, convirtiendo a estas nuevas entidades supranacionales en auténticos agentes político-sociales del nuevo orden mundial. Todo ello - unido al desarrollo espectacular de las comunicaciones y a la intensificación, preeminencia y supeditación a la innovación tecnológica- ha traído consigo un nuevo discurso hegemónico, acelerando la implantación social de los valores del individualismo. Esta nueva realidad ha acarreado una mayor desigualdad, cuya razón radica en el hecho de que la expansión del capitalismo se guía por la búsqueda de la máxima ganancia para las empresas, desatendiendo las cuestiones relacionadas con la distribución de la riqueza, o la de ofrecer empleo en mayor cantidad o calidad (cfr. Amin, 1999: 30).

Con el reclamo de promover la responsabilidad y la competitividad de los individuos y la iniciativa espontánea de la «sociedad civil», fruto del discurso de neoconservadores y neoliberales -con la aquiescencia de posiciones cercanas a la socialdemocracia y anteriormente señaladas- el Estado ha ido relegando y delegando sus responsabilidades como garante del interés colectivo. A medida que los servicios públicos como la salud, la educación, la vivienda, la energía eléctrica o el agua potable (referidos todos ellos a la categoría de bienes y prestaciones proporcionados por el Estado, a modo de derechos sociales que garanticen los requisitos mínimos de una vida digna y aseguren la satisfacción de las necesidades básicas) se han ido privatizando y entrando en la lógica del mercado, han perdido su 
función originaria como componentes inalienables de los derechos ciudadanos, y se han convertido en meras mercancías de cambio entre proveedores privados y clientes que actúan en el mercado al margen de cualquier consideración social, y, además, al margen de cualquier responsabilidad gubernamental de atender las necesidades primordiales de la población.

El modelo de globalización que se está imponiendo no es precisamente el de globalizar la solidaridad o los derechos fundamentales (incluidos los derechos sociales), sino el de la globalización, que sigue la pauta neoliberal de desregularización del mercado y la búsqueda de la máxima riqueza. Además, este proyecto de globalización, a modo de «sentido común neoliberal», ha instaurado prejuicios y argumentos culturales y políticos que han arraigado fuertemente en los sectores hegemónicos de la sociedad, los cuales, una vez adquirida la convicción de que su propuesta era la única posible y viable, han difundido machaconamente esta certidumbre entre el resto de la sociedad mediante la siguiente máxima inapelable: todo lo relacionado con lo estatal es «malo e ineficiente», mientras que lo vinculado con el mercado es «bueno y eficiente».

Y con estas «evidencias» el trecho es muy corto para la consideración del modelo neoliberal como el único racional, instaurando a renglón seguido una ética que sentencie que las acciones humanas pueden y deben ser racionales en su principio, en su conducta y en su finalidad (cfr. Morín, 1984: 293).

Como consecuencia de todo eso, para los dueños del capital y los valedores del neoliberalismo, los países y los Estados son simplemente mercados, los ciudadanos consumidores y la globalización neoliberal la única vía posible de civilización. Por ello, ya es coherente volcarse en la eliminación de las barreras estatales y nacionales que impiden el libre flujo de las mercancías y capitales, y, siguiendo esta lógica, la protección de las personas frente a las incertidumbres económico-sociales y la garantía de los derechos básicos de los ciudadanos (que en algún momento fueron los pilares del Estado del Bienestar) han sido desplazados por un Estado mínimo, un «paraíso de las oportunidades individuales», donde los servicios públicos son vendidos como mercancías. 
El desplazamiento del Estado y la absoluta imposición del mercado en la actividad económica han traído consigo formas crecientes de exclusión social y han elevado los niveles de desempleo y pobreza, además de agudizar el desequilibrio y la polarización entre los sectores más beneficiados y perjudicados en las distintas comunidades.

De este modo, en la medida en que el concepto moderno de ciudadanía hace referencia a la autonomía de los sujetos y a derechos basados en la igual dignidad, no se puede considerar a los individuos en abstracto, sino que hay que reconocerlos con diferencias sociales, por lo que las garantías sociales son imprescindibles para la realización de los valores de la ciudadanía. La ciudadanía no se puede ejercer sin dignidad, y la salvaguarda de este merecimiento está condicionada a unas condiciones mínimas que van más allá del mero reconocimiento formal de la igualdad jurídica. Hacer frente a este reto es apostar por un futuro más justo, y no hacerlo, al contrario, es permitir que la lógica de la desigualdad y la dictadura del mercado se imponga irremediablemente. Es la hora del Estado democrático 


\section{Referencias}

Alexy, R., 1997, Teoría de los derechos fundamentales. Trad. E. Garzón Valdés. Madrid: Centro de Estudios Constitucionales.

Alexy, R., 2004, El concepto y la validez del derecho. Trad. J. M. Seña. Barcelona: Gedisa.

Amin, S., 1999, El capitalismo en la era de la globalización. Trad. R. Grasa. Barcelona: Paidós.

Anchustegui Igartua, E., 2010, “Ciudadanía y derechos sociales", en: Lan Harremanak. Revista de Relaciones Laborales, no 22, Universidad del País Vasco / Euskal Herriko Unibertsitatea, pp. 151-165.

Anchustegui Igartua, E., 2012, "Republicanismo político y ciudadanía social”, en: ARAUCARIA. Revista Iberoamericana de Filosofía, Política y Humanidades, Monográfico Democracia, Ciudadanía y Mercado, coordinado por Esteban Anchustegui Igartua, nº 27, junio 2012.

Aristóteles, 1941, La Política. Versión de Patricio de Azcárate Corral. Buenos Aires: Espasa-Calpe, Colección Austral.

Baccelli, L., 1994, "Cittadinanza e appartenenza”, en: D. Zolo (ed.) La cittadinanza: Appartenza, identità, diritti. Roma-Bari: Laterza, pp. 129-165.

Barbalet, J., 1988, Citizenship: Rights, Struggle and Class Inequality. Minneapolis: University of Minnesota Press.

Baron, H., 1993, En busca del humanismo cívico florentino. Trad. M. A. Camacho Ocampo. México: Fondo de Cultura Económica.

Beiner, R., 1997, "Liberalismo, nacionalismo, ciudadanía: tres modelos de comunidad política", en: Revista internacional de filosofía política, nํㅜ 10, Madrid, pp. 5-22.

Bellah, R., et al., 1985, Habits of the Heart. Berkeley: University of California Press, en español, 1989, Hábitos del corazón. Madrid: Alianza.

Berlin, I., 2002, Liberty (edición revisada y ampliada de Four Essays On Liberty). Oxford University Press.

Brillante, A., 1994, "Cittadinanza e democrazia", en: D. Zolo (ed.) La cittadinanza: Appartenza, identità, diritti. Roma-Bari: Laterza, pp. 203-221.

Colom, F., 1994, "Dilemas de regulación social en las sociedades democráticas", en Revista internacional de filosofía política, no 4, Madrid, pp. 41-60.

Contreras Peláez, F. J., 1994, Derechos Sociales: Teoría e Ideología. Madrid: Tecnos.

Cossío Díaz, J. R., 1989, Estado social y derechos de prestación. Madrid: Centro de Estudios Constitucionales. 
Dahrendorf, R., 1997, "La naturaleza cambiante de la ciudadanía”, en: La Política: Revista de estudios sobre el estado y la sociedad, no 3 (octubre), Barcelona, Paidós, pp. 139-149.

De Jasay, A., 1993, El Estado. La lógica del poder político. Trad. Rafael Capaos Valderrama. Madrid: Alianza.

De Lucas, J., 1989, "Sobre la justificación de !a democracia representativa”, en: Doxa. nº. 6, Alicante; Universidad de Alicante, pp. 187-199.

Gargarella, R., 1999, Las teorías de la justicia después de Rawls, Barcelona: Paidós.

Gordon, S., 2003, "Ciudadanía y derechos ¿criterios redistributivos?", CEPAL-Serie Políticas Sociales no 70, Santiago de Chile. Publicación de las Naciones Unidas. También en Revista Mexicana de Sociología (Vol. LXIII, No 3, julio-septiembre, 2001).

Habermas, J., 1998, Facticidad y validez. Trad. M. Jiménez Redondo, Madrid: Trotta.

Habermas, J., 1998, "Soberanía popular como procedimiento", en J. Habermas. Facticidad y Validez. Madrid: Trotta, pp. 589-618.

Habermas, J., 1999, "Tres modelos normativos de democracia", en: J. Habermas. La Inclusión del Otro. Trad. J. C. Velasco Arroyo. Barcelona: Paidos, pp. 231-246.

Kant, I., 1989, Metafísica de las costumbres. Trad. A. Cortina y J. Conill, Madrid: Tecnos.

MacIntyre, A., 1995, “Is Patriotism a Virtue?", en: R. Beiner (ed.) Theorizing Citizenship. Albany (NY), State University of New York, pp. 209-228.

Marshall, T. H. [1949], 1997, "Ciudadanía y clase social”, en: REIS. Revista Española de Investigaciones Sociológicas, no 79, Madrid, pp. 297-346.

Martínez, J. L., 2007, "La Religión en una sociedad democrática, pluralista y multicultural: creyentes que son ciudadanos, ciudadanos que son creyentes", en G. Uribarri (ed.) Contexto y nueva evangelización, Salamanca: Universidad Pontificia Comillas, pp. 2023-278.

Marx, K., 1997, La cuestión judía. Trad. A. Hermosa, Madrid: Santillana.

Morín, E., 1984, Ciencia con Consciencia. Traducción de Ana Sánchez. Barcelona: Antrophos.

Nicolet, C., 1982, L'idée republicaine en France (1789-1924), Gallimard, París.

Oliver, D. \&. Heater, D., 1994, The foundations of citizenship. Hertfordshire: Harvester Wheatsheaf. 
Ovejero, F., 1997, "Tres ciudadanos y el bienestar", en: La Política: Revista de estudios sobre el estado y la sociedad, no 3 (octubre), Barcelona: Paidós, pp. 93-116.

Peces-Barba. G., 1988, Escritos sobre Derechos Fundamentales, Madrid: Eudema.

Pocock, J. G. A., 1975, The machiavellian moment. New Jersey: Princeton University Press, en español, El momento maquiavélico, Madrid: Tecnos, 2002.

Schumpeter, J. A., 1984, Capitalismo, socialismo y democracia. Trad. Atanasio Sánchez. Barcelona: Folio.

Skinner, Q., 1998, Maquiavelo. Trad. M. Benavides. Madrid: Alianza.

Skinner, Q. - Bock, G. - Viroli, M., 1990, Machiavelli and Republicanism, Cambridge University Press, New York.

Spitz, J. F., 1995, La liberté politique. París: PUF.

Taylor Ch., 1990, “El atomismo”, en J. Betegón - J. R. de Páramo (coords.) Derecho y moral, ensayos analíticos. Barcelona: Ariel, pp. 107-124.

Taylor, Ch., 1998, Ética de la autenticidad. Trad. P. Carbajosa Pérez. Barcelona: Paidós.

Zolo, D., 1994 (ed.) La cittadinanza: Appartenza, identità, diritti. RomaBari: Laterza. 